
\title{
25 Research Square \\ Influence of trends in hospital volume over time on patient outcomes for high-risk surgery
}

Cécile Payet ( $\nabla$ cecile.payet02@chu-lyon.fr )

Hospices Civils de Lyon https://orcid.org/0000-0001-5220-4070

\section{Stéphanie Polazzi}

Hospices Civils de Lyon

Jean-Christophe Lifante

Hospices Civils de Lyon

\section{Eddy Cotte}

Hospices Civils de Lyon

\section{Daniel Grinberg}

Hospices Civils de Lyon

Matthew J Carty

Brigham and Women's Hospital

\section{Stéphane Sanchez}

Centre Hospitalier de Troyes

\section{Muriel Rabilloud}

Hospices Civils de Lyon

\section{Antoine Duclos}

Hospices Civils de Lyon

\section{Research article}

Keywords: volume-outcome, trend, surgery

Posted Date: February 25th, 2020

DOI: https://doi.org/10.21203/rs.2.17868/v2

License: (c) (1) This work is licensed under a Creative Commons Attribution 4.0 International License.

Read Full License

Version of Record: A version of this preprint was published at BMC Health Services Research on April 1st, 2020. See the published version at https://doi.org/10.1186/s12913-020-05126-4. 


\section{Abstract}

Background The "practice makes perfect" concept considers the more frequent a hospital performs a procedure, the better the outcome of the procedure. We aimed to study this concept by investigating whether patient outcomes improve in hospitals with a significantly increased volume of high-risk surgery over time and whether a learning effect existed at the individual hospital level. Methods We included all patients who underwent one of ten digestive, cardiovascular and orthopaedic procedures between 2010 and 2014 from the French nationwide hospitals database. For each procedure, we identified three groups of hospitals according to volume trend (increased, decreased, or no change). In-hospital mortality, reoperation, and unplanned hospital readmission within 30 days were compared between groups using Cox regressions, taking into account clustering of patients within hospitals and potential confounders. Individual hospital learning effect was investigated by considering the interaction between hospital groups and procedure year. Results Over 5 years, 759,928 patients from 694 hospitals were analysed. Patients' mortality in hospitals with procedure volume increase or decrease over time did not clearly differ from those in hospitals with unchanged volume across the studied procedures (e.g., Hazard Ratios [95\%] of 1.04 [0.93-1.17] and 1.08 [0.97-1.21] respectively for colectomy). Furthermore, patient outcomes did not improve or deteriorate in hospitals with increased or decreased volume of procedures over time (e.g., 1.01 [0.95-1.08] and 0.99 [0.92-1.05] respectively for colectomy). Conclusions Trend in hospital volume over time does not appear to influence patient outcomes based on real-world data.

\section{Background}

The relationship between hospital surgical procedures volume and related mortality has been extensively investigated over the past several decades [1]. Numerous studies have reported that patients who undergo operations in hospitals performing a high number of procedures achieve better outcomes [2-10]. Based on these findings, some countries have strived to consolidate specific procedures in high-volume hospitals, with varying results $[7,8,11,12]$. Consequently, significant methodological flaws regarding the validity of the volume-outcome relationship and the definition of evidence-based volume thresholds have been pointed out [13-17]. Although high-volume hospitals may provide, on average, safer care than lowvolume hospitals, some high-volume hospitals may perform poorly while some low-volume hospitals may perform well [18-20]. Nonetheless, hospital-volume continues to be used as a proxy quality metric for high-risk surgeries.

While a volume-outcome relationship may exist for certain procedures, the explanatory mechanisms of this association have not been fully elucidated. The concept of the volume-outcome relationship is based on the assumption that hospitals that perform a complex procedure more frequently have better outcomes and could manage adverse events more effectively than those who rarely perform the procedure $[21,22]$. In the same manner that surgeon or team experience may determine a procedurespecific learning curve $[23,24]$, this assumption may recapitulate the "practice-makes-perfect" dogma at the institutional level $[25,26]$. Most prior studies on volume-outcome relationship have compared outcomes between low- and high-volume hospitals at some point. However, they did not consider the 
temporal relationship that may exist between volume and outcome under the influence of a dynamic learning effect. Consequently, it remains unclear whether changes in hospital procedural volumes influence patient safety. In this nationwide study, we took another look at the volume-outcome relationship in high-risk surgery by evaluating, at the individual hospital level, the association between trends in volume and patient outcome over time.

\section{Methods}

\section{Study design and data source}

We performed a nationwide observational study to determine whether patient outcomes improve in hospitals with a significantly increased volume of high-risk surgery over time and whether a learning effect existed at the individual hospital level. We first defined three groups of hospitals according to the trend of the volume of surgical procedures over a 5-year period, that is, for a given hospital, the volume of a specific procedure increased, decreased, or did not change. Second, we compared the average patient outcomes and their evolution over time between these three defined hospital groups, taking into account potential confounding factors related to hospital and patient characteristics. To test the robustness of our results, we repeated this scheme across ten high-risk surgical and interventional procedures in various specialties and considered different patient outcomes.

This study used the French Medical Information System (Programme de Médicalisation des Systèmes d'Information [PMSI]), which is a large acute rate hospital database with prospectively collected data from all public and private hospitals in France. The database is routinely implemented for the purpose of care reimbursement, which in turn led to strong accuracy and exhaustive collection of data. Thus, no patients were assumed to be lost to follow-up during the study period. Moreover, the PMSI has a system of coding with strict variable definitions and a subset of records audited on a regular basis to avoid coding errors. Inpatient stays are converted into one Diagnosis-Related Group based on standard discharge abstracts containing compulsory information about the patient, primary and secondary diagnoses using the International Classification of Diseases (10th revision - ICD-10 codes), emergency status, and procedural codes associated with the care provided using a detailed classification.

From the PMSI database, we extracted data on patient demographics, co-morbidities according to the Elixhauser algorithm [27], the type and emergency context of the procedure, and discharge by transfer to another acute care hospital. We also characterized each hospital according to its status (i.e., teaching, public, or private for-profit), degree of specialization (i.e., proportion of admissions logged for each studied procedure in the related surgical department), and attraction rate (i.e., the proportion of patients living in another geographical area than that of the hospital location where they underwent each studied procedure). To define patients' socioeconomic status, we extracted the median income of the patients' residence provided by the National Institute of Statistics and Economic Studies.

This study was approved by the National Data Protection Commission (Commission Nationale Informatique et Libertés) in accordance with French ethical directives and was registered on 
clinicaltrial.gov (NCT02788331).

\section{Study population and outcomes}

We included all patients who underwent one of the following ten procedures from January 1, 2010 to December 31, 2014: resection of a digestive cancer (i.e., colectomy, proctectomy, esophagectomy, gastrectomy, and pancreatectomy), intervention on the cardiovascular system (i.e., percutaneous coronary intervention [PCI]), coronary-artery bypass grafting [CABG], carotid endarterectomy, and elective repair of abdominal aortic aneurysm [AAA]), and urgent hip fracture repair (Appendix S1). The choice to focus on those procedures was guided by available evidence suggesting the existence of volumeoutcome relationships based on cross-sectional studies [2-5]. Each procedure was identified from the PMSI database by combining specific diagnoses and procedural codes.

For each studied procedure, all patients from hospitals not performing at least one procedure per year were removed from the dataset. Furthermore, patients $<18$ years old, who experienced ambulatory care, or with data inaccuracies were excluded. After the washout for every procedure since 2009 , we only selected the first hospitalization of each patient identified as the index stay (except in the case of hip fracture, in which two stays were potentially included if the second stay occurred at least 30 days after the first discharge), using unique, anonymous patient numbers that linked all his/her stays in acute care.

The following patient outcomes were analysed: in-hospital mortality, reoperation, and potentially avoidable hospital readmission. In-hospital mortality and reoperation were defined as death and reoperation, respectively, within a maximum of 30 days post-procedure, whereas potentially avoidable readmission was studied within 30 days of the index stay discharge $[28,29]$.

\section{Statistical analysis}

To classify hospitals based on their volume change over time, we calculated individual hospital volume for each of the ten studied procedures as the total number of patients treated by each hospital within each year. Subsequently, hospitals were divided into three groups based on whether their annual procedure volumes were increasing, decreasing or remaining stable over a 5-year period. We used the random slopes of multilevel Poisson models, taking into account the annual repeated measures of hospital volume for each procedure. These slopes were categorized into three groups using the K-means method to avoid arbitrary determination of thresholds and to account for intra-group variances that could vary [30].

For each procedure, to determine if mortality was altered in patients admitted to hospitals with significantly increased volume changes over time and if a learning effect existed at the individual hospital level, we used cox regressions, taking into account the clustering effect of patients within hospitals with robust variance estimator (i.e., patients treated and outcomes within a particular hospital tended to be more similar than those in another hospital), the follow-up that varied from one patient to another, and the hospital discharge that represented a censure of outcome [31, 32]. Furthermore, hospital 
learning effect was investigated by examining the interaction between hospital groups and year of procedure. To adjust mortality for case mix variations, we considered patient (age, gender, Elixhauser list of comorbidities, type and year of procedure, transfer, emergency admission, and median income) and hospital (hospital status, volume of procedures, specialization degree, and attraction rate) characteristics. Restricted cubic splines were used for continuous variables in the adjustment scheme [33].

To test the robustness of our results, we repeated this analysis across secondary outcomes (reoperation and unplanned hospital readmission) using Fine and Gray's models to consider the, competing risk of death. Model estimates were presented as adjusted hazards ratios (HR) with corresponding $95 \%$ confidence interval $(95 \% \mathrm{Cl})$. Data manipulation and analyses were performed using SAS version 9.4 (SAS Institute Inc, Cary, NC) and R version 3.2.1 (R Foundation for Statistical Computing, Vienna, Austria) software.

\section{Results}

\section{Characteristics of patients and hospitals}

Over five years, 759,928 patients were admitted in 694 French hospitals to undergo one of ten procedures related to digestive cancer resection, cardiovascular system intervention, or hip fracture repair. Table 1 shows that not all procedures were performed in all hospitals. The number of hospitals performing each procedure ranged from 45 for CABG to 610 for colectomy. Furthermore, hospital volume varied from one procedure to another, averaging from 29 for gastrectomy to 1,269 for $\mathrm{PCl}$.

Total number of patients ranged from 2,296 for esophagectomy to 280,369 for $\mathrm{PCl}$ (Table 2). Regarding adverse event rates between studied procedures (Table 3), patients who underwent esophagectomy had the highest risk of death (5.4\%), reoperation (15.1\%) and unplanned hospital readmission $(15.7 \%)$, while those who underwent carotid endarterectomy had the lowest risk of death $(0.9 \%)$ and unplanned hospital readmission (5.0\%) and those who underwent hip fracture repair had the lowest risk of reoperation (2.5\%).

\section{Relationship between trend in hospital volume and surgical outcomes}

Figure 1 shows hospital distribution according to the trend in the volume of procedures. The highest proportion of hospitals with unchanged volume was for hip fracture repair $(70.8 \%)$, while that of hospitals with an increasing volume and those with decreasing volume was for carotid endarterectomy $(30.1 \%)$ and for esophagectomy (56.4\%), respectively. Volume change rate per year in hospitals experiencing volume increase or decrease according to procedures are presented in Table E1.

Figure 2a shows that patient mortality were not different among the hospital groups except for pancreatectomy where the mortality rate was higher in hospitals with increasing volume than in hospitals with unchanged volume (HR 95\% $\mathrm{Cl} 1.39$ [1.02-1.90], $\mathrm{p}=0.035)$. Regarding the other outcomes (Figure E2a and E3a), there was also no difference for most procedures even if some results were inconsistent. 
Unplanned hospital readmission rate was higher in hospitals with increasing volume for esophagectomy (1.56 [1.08-2.25], $\mathrm{p}=0.017)$ and carotid endarterectomy (1.13 [1.01-1.27], $\mathrm{p}=0.035)$. Reoperation and unplanned hospital readmission rates were higher in hospitals with decreasing volume (1.31 [1.07-1.61], $p=0.010$ and 1.34 [1.16-1.56], $p<0.001$ respectively) for carotid endarterectomy. However, reoperation rate was lower in hospitals with decreasing volume $(0.43$ [0.22-0.82], $p=0.011)$ for CABG.

Regarding potential hospital learning effect (Figure 2b), no association was found between volume trend and mortality over time except for esophagectomy where mortality decreased over time in hospitals with increasing volume (0.65 [0.51-0.83], $\mathrm{p}<0.001)$. Regarding the other outcomes (Figure E2b and E3b), there were also no association except for $\mathrm{CABG}$ where reoperation rate was lower over time in hospitals with increasing volume (0.71 [0.53-0.94], $p=0.018)$ and higher in those with decreasing volume (1.53 [1.301.81], $p<0.001)$, and for AAA repair where it tended to be lower over time in hospitals with decreasing volume for AAA repair $(0.78$ [0.64-0.96], $p=0.018)$.

\section{Discussion}

We investigated the trends in hospital volume and patient outcomes over time across ten high-risk procedures to better understand the explanatory mechanisms of volume-outcome relationship. We focused on the "practice-makes-perfect" dogma and assumed that hospitals gain expertise from repeating specific surgical care, thereby leading to improved performance. However, analyses revealed generally no difference in patient outcomes in hospitals with volume change over time. In the same way outcomes did not improve or diminish in hospitals with an increasing or decreasing volume of procedures, respectively, which in turn does not support the existence of a robust learning effect.

Few prior studies examined the temporal relationship between trends in hospital volume and patient outcomes and they showed contrasting results. These studies involved a limited sample of hospitals and investigated inpatient mortality and/or readmission within 30 days [34-36]. Two studies in trauma centres showed that increasing volume was associated with improving outcomes whereas decreasing volume was associated with worsening outcomes [35,36]. Another study focused on hip fracture and obtained consistent results with our study, showing that hospitals performing more surgeries over time did not experience outcomes improvement [34]. In our study, to corroborate the "practice-makes-perfect" dogma, we evaluated the consistency of results in a set of distinct procedures. However, we did not find at the hospital level the learning curve that commonly exists for surgeons or surgical teams experiencing improved performance with higher case volume [23,24]. Several factors may contribute to the relationship between team familiarity and performance, which could prevent the occurrence of intraoperative event. These factors include improved ability to anticipate the actions of other team members, a heightened willingness to relate with one another, and a greater sense of trust [23]. Surgeons who operate together need to continually interpret each other's cues, both verbal and nonverbal, and to adjust their actions accordingly to stay coordinated. These learning effects refer to human willingness to progress both individually and collectively during the procedure to prevent intraoperative patient morbidity. Furthermore, we endeavoured revealing a potential learning effect at the hospital level through 
a gradual optimization of surgical care process with case repetition. Accordingly, we not only considered the operating room activities but also studied the ability of hospital systems to prevent postoperative complications or take actions necessary to mitigate untoward consequences. A hospital's proficiency in minimizing failure to rescue could be related to a variety of factors, such as available resources and perioperative care organization [37]. The quality of recruitment, preoperative evaluation, anaesthetic management, postoperative nursing, patient follow-up, and an integrated care system with enhanced healthcare workers collaboration are also essential for safe surgery.

This study has some potential limitations. Data were extracted from large hospital databases, which have been initially implemented for billing inpatient stays. Thus, motivation of data coders was possibly influenced by financial stakes rather than epidemiological accuracy [38]. Risk adjustment could only account for factors that can be identified and measured accurately from these data [39]. Although we considered hospital and patient characteristics in the adjustment scheme, this may not be sufficient to ascertain the effect of the differential case mix on surgical outcome. Moreover, we could not adjust patient outcomes for the volume of procedures and learning curve at the individual surgeon level as no data are available. Consequently, the hospital learning effect independent of the surgeon's ability could not be estimated. We also could not identify whether the increase in volume was due to an increase in surgeon number performing the procedure in the hospital or due to an increase in the number of procedures by the same surgeons. Furthermore, specific complications for each procedure, such as major adverse cardiac and cerebrovascular events for CABG or stroke for carotid surgery, were not monitored. To analyse jointly the results across various procedures, we opted for generic outcomes. The unclear link between those outcomes and surgical care quality may explain the difficulties in revealing the existence of a potential hospital learning effect. This may also be attributable to the fact that many surgical procedures have been performed for a long time and hospitals may have achieved the benefits of learning well before the study period, precluding our ability to evidence practice-makes-perfect. Hence, learning effects would be easier to reveal with relatively new procedures, wherein hospitals initiate several changes in the facilities and staff for safe surgery. Finally, a delay in the effect of the change in hospital volume on patient outcomes is possible. Assuming that hospitals would require a sustained volume increase for several years to produce an observable effect on patient outcomes, we may have failed to identify a learning effect because of the limited duration of follow-up of hospital behaviour.

Our findings have implications for the efforts aimed at surgical care improvement. We studied a wide range of procedures to investigate the dynamics of volume-outcome relationship within hospitals and showed that a significant increase in volume of procedures over time does not necessarily enhance patient safety. Accordingly, temporal variation in the volume of procedures would not seem a valid surrogate of surgical quality for guiding hospitals' pay-for-performance strategies or providing licensure of surgical practice. The underlying mechanism of volume-outcome relationship based on the practicemakes-perfect dogma is not supported by tangible observable evidence. Thus, patient outcomes at the individual hospital level would be influenced by factors other than potential learning effect. This may help explain the low mortality [18-20] and the good outcomes [40] in some low-volume hospitals, and possibly some other factors enabled hospitals to achieve excellent outcomes independent of the volume 
of procedures. For example, higher surgical quality could be attributed to better care organization or the availability of effective medical technologies. Current health policies promote centralizing specific procedures in high-volume referral centres to improve patient outcomes. However, such could result in disparities in patient access to safe surgery, unreasonable travel burdens, and potential delays in operations [41-43]. Hence, in areas where access to referral centres is limited, importing optimal practices may be essential to delivering high-quality surgery. Providing homogeneous surgical quality across the country represents an alternative to centralization, which requires the identification of best systems to achieve excellent outcome and effective strategies to implement these systems from one hospital to another.

\section{Declarations}

Ethics approval and consent to participate: This study was strictly observational and based on anonymous data. Therefore, in accordance with the French ethical directives, it did not require the written informed consent from the participants or the authorization from an ethic committee. This study was approved by the National Data Protection Commission (Commission Nationale Informatique et Libertés) in accordance with French ethical directives and was registered on clinicaltrial.gov (NCT02788331).

Consent for publication: Not applicable

Availability of data and materials: The data that support the findings of this study are available from the French Medical Information System maintained by the Technical Agency for Information on Hospital Care. However, restrictions apply to the availability of these data, which were used under license for the current study, and so are not publicly available.

Competing interests: The authors declare that they have no competing interests

Funding: This study was supported by a grant from the Programme de Recherche sur la Performance du Système des Soins 2015 of the French Ministry of Health. The funding source had no involvement in the study design; the collection, analysis, and interpretation of data; the writing of the study; or the decision to submit the article for publication. The researchers were independent from the funder.

Authors' contributions: $\mathrm{CP}$ and $\mathrm{AD}$ had full access to all of the data in the study and takes responsibility for the integrity of the data and the accuracy of the data analysis. Study concept: $C P, S P, J C L, E C, S S, A D$; study design: $C P, S S, M R, A D$; acquisition of data: $S P, A D$; analysis of data: $C P, M R, A D$; interpretation of data: $C P, S P, J C L, E C, D G, M J C, M R, A D$; drafting of the manuscript: $C P, S P, A D$; critical revision of the manuscript for important intellectual content: CP, SP, JCL, EC, DG, MJC, SS, MR, AD; approved current version of manuscript of publication in its current form: CP, SP, JCL, EC, DG, MJC, SS, MR, AD.

Acknowledgements: Not applicable

\section{References}


1. Payet C, Lifante J-C, Carty MJ, Rabilloud M, Duclos A. Methodological Quality of Surgical Mortality Studies Using Large Hospital Databases: A Systematic Review. Annals of Surgery. 2017;265:1113-8.

2. Dudley RA, Johansen KL, Brand R, Rennie DJ, Milstein A. Selective Referral to High-Volume Hospitals: Estimating Potentially Avoidable Deaths. JAMA. 2000;283:1159.

3. Gandjour A, Bannenberg A, Lauterbach KW. Threshold Volumes Associated With Higher Survival in Health Care: A Systematic Review. Medical Care. 2003;41:1129-41.

4. Halm EA, Lee C, Chassin MR. Is Volume Related to Outcome in Health Care? A Systematic Review and Methodologic Critique of the Literature. Annals of Internal Medicine. 2002;137:511.

5. Killeen SD, O'Sullivan MJ, Coffey JC, Kirwan WO, Redmond HP. Provider volume and outcomes for oncological procedures. British Journal of Surgery. 2005;92:389-402.

6. Luft HS, Hunt SS, Maerki SC. The volume-outcome relationship: practice-makes-perfect or selectivereferral patterns? Health Serv Res. 1987;22:157-82.

7. Gordon TA, Bowman HM, Tielsch JM, Bass EB, Burleyson GP, Cameron JL. Statewide regionalization of pancreaticoduodenectomy and its effect on in-hospital mortality. Ann Surg. 1998;228:71-8.

8. Learn PA, Bach PB. A decade of mortality reductions in major oncologic surgery: the impact of centralization and quality improvement. Med Care. 2010;48:1041-9.

9. Birkmeyer JD, Dimick JB, Staiger DO. Operative mortality and procedure volume as predictors of subsequent hospital performance. Ann Surg. 2006;243:411-7.

10. Reames BN, Ghaferi AA, Birkmeyer JD, Dimick JB. Hospital volume and operative mortality in the modern era. Ann Surg. 2014;260:244-51.

11. Finks JF, Osborne NH, Birkmeyer JD. Trends in hospital volume and operative mortality for high-risk surgery. N Engl J Med. 2011;364:2128-37.

12. de Cruppé W, Ohmann C, Blum K, Geraedts M. Evaluating compulsory minimum volume standards in Germany: how many hospitals were compliant in 2004? BMC Health Serv Res. 2007;7:165.

13. Kim W, Wolff S, Ho V. Measuring the Volume-Outcome Relation for Complex Hospital Surgery. Appl Health Econ Health Policy. 2016;14:453-64.

14. LaPar DJ, Kron IL, Jones DR, Stukenborg GJ, Kozower BD. Hospital procedure volume should not be used as a measure of surgical quality. Ann Surg. 2012;256:606-15.

15. Livingston EH, Cao J. Procedure volume as a predictor of surgical outcomes. JAMA. 2010;304:95-7.

16. Duclos A, Lifante J-C. Hospital Administrative Data Should Not be Used to Study Thyroid Surgery Outcomes. Ann Surg. 2018;267:e78.

17. Sund R. Modeling the volume-effectiveness relationship in the case of hip fracture treatment in Finland. BMC Health Serv Res. 2010;10:238.

18. Horwitz LI, Lin Z, Herrin J, Bernheim S, Drye EE, Krumholz HM, et al. Association of hospital volume with readmission rates: a retrospective cross-sectional study. BMJ. 2015;350:h447.

19. Kanhere HA, Trochsler MI, Kanhere MH, Lord AN, Maddern GJ. Pancreaticoduodenectomy: outcomes in a low-volume, specialised Hepato Pancreato Biliary unit. World J Surg. 2014;38:1484-90. 
20. Goldschlager T, Selvanathan S, Walker DG. Can a "novice" do aneurysm surgery? Surgical outcomes in a low-volume, non-subspecialised neurosurgical unit. J Clin Neurosci. 2007;14:1055-61.

21. Jha AK. Back to the Future: Volume as a Quality Metric. JAMA. 2015;314:214-5.

22. Gonzalez AA, Dimick JB, Birkmeyer JD, Ghaferi AA. Understanding the volume-outcome effect in cardiovascular surgery: the role of failure to rescue. JAMA Surg. 2014;149:119-23.

23. Xu R, Carty MJ, Orgill DP, Lipsitz SR, Duclos A. The teaming curve: a longitudinal study of the influence of surgical team familiarity on operative time. Ann Surg. 2013;258:953-7.

24. Maruthappu M, El-Harasis MA, Nagendran M, Orgill DP, McCulloch P, Duclos A, et al. Systematic review of methodological quality of individual performance measurement in surgery. Br J Surg. 2014;101:1491-8; discussion 1498.

25. Flood AB, Scott WR, Ewy W. Does practice make perfect? Part I: The relation between hospital volume and outcomes for selected diagnostic categories. Med Care. 1984;22:98-114.

26. Flood AB, Scott WR, Ewy W. Does practice make perfect? Part II: The relation between volume and outcomes and other hospital characteristics. Med Care. 1984;22:115-25.

27. Quan H, Sundararajan V, Halfon P, Fong A, Burnand B, Luthi J-C, et al. Coding algorithms for defining comorbidities in ICD-9-CM and ICD-10 administrative data. Med Care. 2005;43:1130-9.

28. Halfon P, Eggli Y, van Melle G, Chevalier J, Wasserfallen JB, Burnand B. Measuring potentially avoidable hospital readmissions. J Clin Epidemiol. 2002;55:573-87.

29. Halfon P, Eggli Y, Prêtre-Rohrbach I, Meylan D, Marazzi A, Burnand B. Validation of the potentially avoidable hospital readmission rate as a routine indicator of the quality of hospital care. Med Care. 2006;44:972-81.

30. Hartigan JA, Wong MA. Algorithm AS 136: A K-Means Clustering Algorithm. Applied Statistics. 1979;28:100.

31. Varadhan R, Weiss CO, Segal JB, Wu AW, Scharfstein D, Boyd C. Evaluating health outcomes in the presence of competing risks: a review of statistical methods and clinical applications. Med Care. 2010;48 6 Suppl:S96-105.

32. Glidden DV, Vittinghoff E. Modelling clustered survival data from multicentre clinical trials. Stat Med. 2004;23:369-88.

33. Marrie RA, Dawson NV, Garland A. Quantile regression and restricted cubic splines are useful for exploring relationships between continuous variables. J Clin Epidemiol. 2009;62:511-517.e1.

34. Hamilton $\mathrm{BH}, \mathrm{Ho}$ V. Does practice make perfect? Examining the relationship between hospital surgical volume and outcomes for hip fracture patients in Quebec. Med Care. 1998;36:892-903.

35. Brown JB, Rosengart MR, Kahn JM, Mohan D, Zuckerbraun BS, Billiar TR, et al. Impact of Volume Change Over Time on Trauma Mortality in the United States. Ann Surg. 2017;266:173-8.

36. Marcin JP, Romano PS. Impact of between-hospital volume and within-hospital volume on mortality and readmission rates for trauma patients in California. Crit Care Med. 2004;32:1477-83. 
37. Ghaferi AA, Birkmeyer JD, Dimick JB. Hospital volume and failure to rescue with high-risk surgery. Med Care. 2011;49:1076-81.

38. lezzoni LI. Assessing quality using administrative data. Ann Intern Med. 1997;127 8 Pt 2:666-74.

39. Lilford R, Mohammed MA, Spiegelhalter D, Thomson R. Use and misuse of process and outcome data in managing performance of acute medical care: avoiding institutional stigma. Lancet. 2004;363:1147-54.

40. Maa J, Gosnell JE, Gibbs VC, Harris HW. Exporting excellence for Whipple resection to refine the Leapfrog Initiative. J Surg Res. 2007;138:189-97.

41. Stitzenberg KB, Sigurdson ER, Egleston BL, Starkey RB, Meropol NJ. Centralization of cancer surgery: implications for patient access to optimal care. J Clin Oncol. 2009;27:4671-8.

42. Finlayson SR, Birkmeyer JD, Tosteson AN, Nease RF. Patient preferences for location of care: implications for regionalization. Med Care. 1999;37:204-9.

43. Birkmeyer JD, Siewers AE, Marth NJ, Goodman DC. Regionalization of high-risk surgery and implications for patient travel times. JAMA. 2003;290:2703-8.

\section{Tables}

Table 1 Hospital characteristics by procedure 


\begin{tabular}{|c|c|c|c|c|c|c|c|}
\hline & \multirow{2}{*}{$\begin{array}{l}\text { Hospitals } \\
\text { number }\end{array}$} & \multirow{2}{*}{$\begin{array}{l}\text { Volume of } \\
\text { procedures } \\
\text { mean (SD) }\end{array}$} & \multicolumn{3}{|c|}{ Status } & \multirow{2}{*}{$\begin{array}{l}\text { Specialization } \\
\text { degree }^{\mathrm{a}} \\
\text { mean (SD) }\end{array}$} & \multirow{2}{*}{$\begin{array}{l}\text { Attraction } \\
\text { rate }^{b} \\
\text { mean } \\
\text { (SD) }\end{array}$} \\
\hline & & & Teaching & $\begin{array}{c}\text { Public or private } \\
\text { non-for-profit }\end{array}$ & $\begin{array}{c}\text { Private for } \\
\text { profit }\end{array}$ & & \\
\hline Colectomy & 610 & $141.2(87.5)$ & $\begin{array}{c}30 \\
(4.9 \%)\end{array}$ & $319(52.3 \%)$ & $\begin{array}{c}261 \\
(42.8 \%)\end{array}$ & $5.3(2.4)$ & $\begin{array}{c}13.8 \\
(14.5)\end{array}$ \\
\hline Proctectomy & 522 & $71.0(54.2)$ & $\begin{array}{c}33 \\
(6.3 \%)\end{array}$ & 297 (56.9\%) & $\begin{array}{c}192 \\
(36.8 \%)\end{array}$ & $2.5(2.3)$ & $\begin{array}{c}16.2 \\
(17.3)\end{array}$ \\
\hline Esophagectomy & 62 & $37.0(58.4)$ & $\begin{array}{c}23 \\
(37.1 \%)\end{array}$ & $27(43.5 \%)$ & 12 (19.4\%) & $0.8(1.1)$ & $\begin{array}{c}33.2 \\
(26.7)\end{array}$ \\
\hline Gastrectomy & 343 & $28.5(22.7)$ & $\begin{array}{c}30 \\
(8.7 \%)\end{array}$ & 184 (53.6\%) & $\begin{array}{c}129 \\
(37.6 \%)\end{array}$ & $0.9(0.9)$ & $\begin{array}{c}16.9 \\
(18.2)\end{array}$ \\
\hline Pancreatectomy & 166 & $37.0(39.0)$ & $\begin{array}{c}28 \\
(16.9 \%)\end{array}$ & $83(50.0 \%)$ & $55(33.1 \%)$ & $0.9(0.9)$ & $\begin{array}{c}23.5 \\
(22.3)\end{array}$ \\
\hline PCI & 221 & $\begin{array}{c}1,268.6 \\
(1,086.3)\end{array}$ & $\begin{array}{c}23 \\
(10.4 \%)\end{array}$ & 81 (36.7\%) & $\begin{array}{c}117 \\
(52.9 \%)\end{array}$ & $19.6(10.1)$ & $\begin{array}{c}21.4 \\
(16.5)\end{array}$ \\
\hline CABG & 45 & $516.6(502.2)$ & $\begin{array}{c}22 \\
(48.9 \%)\end{array}$ & $18(40.0 \%)$ & $5(11.1 \%)$ & $7.8(7.7)$ & $\begin{array}{c}49.3 \\
(21.7)\end{array}$ \\
\hline AAA repair & 207 & $77.0(78.5)$ & $\begin{array}{c}23 \\
(11.1 \%)\end{array}$ & $129(62.3 \%)$ & $55(26.6 \%)$ & $2.1(1.8)$ & $\begin{array}{c}24.0 \\
(21.2)\end{array}$ \\
\hline $\begin{array}{l}\text { Carotid } \\
\text { endarterectomy }\end{array}$ & 296 & $215.6(209.1)$ & $\begin{array}{c}19 \\
(6.4 \%)\end{array}$ & $193(65.2 \%)$ & $84(28.4 \%)$ & 47.7 (26.5) & $\begin{array}{c}20.1 \\
(19.6)\end{array}$ \\
\hline $\begin{array}{l}\text { Hip fracture } \\
\text { repair }\end{array}$ & 421 & $558.5(437.9)$ & $\begin{array}{c}23 \\
(5.5 \%)\end{array}$ & 133 (31.6\%) & $\begin{array}{c}265 \\
(62.9 \%)\end{array}$ & $12.9(7.9)$ & $\begin{array}{c}11.9 \\
(12.5)\end{array}$ \\
\hline
\end{tabular}

a Proportion of stays for each studied procedure in the surgical department (expressed as a percentage)

$\mathrm{b}$ Proportion of patients living in another geographical area that the one of hospital location where they underwent each studied procedure (expressed as a percentage)

PCI percutaneous coronary intervention, CABG coronary-artery bypass grafting, AAA abdominal aortic aneurysm

Table 2 Patient characteristics by procedure 


\begin{tabular}{|c|c|c|c|c|c|c|c|}
\hline & $\begin{array}{l}\text { Patient } \\
\text { number }\end{array}$ & $\begin{array}{l}\text { Men } \\
\text { N (\%) }\end{array}$ & $\begin{array}{l}\text { Age } \\
\text { mean } \\
(\mathrm{SD})\end{array}$ & $\begin{array}{l}\text { No. of different Elixhauser } \\
\text { comorbidities }^{\mathrm{a}} \\
\text { Mean (SD) }\end{array}$ & $\begin{array}{c}\text { Median } \\
\text { income, K€ } \\
\text { Mean } \\
\text { (SD) }\end{array}$ & $\begin{array}{l}\text { Emergency } \\
\text { admission } \\
\mathrm{N}(\%)\end{array}$ & $\begin{array}{c}\text { Discharge by } \\
\text { transfer } \\
\mathrm{N}(\%)\end{array}$ \\
\hline Colectomy & 86,102 & $\begin{array}{l}44,994 \\
(52.3)\end{array}$ & $\begin{array}{c}71.6 \\
(12.2)\end{array}$ & $1.8(1.6)$ & 20.4 (3.3) & $13,201(15.3)$ & $2,771(3.2)$ \\
\hline Proctectomy & 37,088 & $\begin{array}{l}22,862 \\
(61.6)\end{array}$ & $\begin{array}{c}68.5 \\
(11.8)\end{array}$ & $1.5(1.5)$ & $20.3(3.2)$ & $1,651(4.5)$ & $1,229(3.3)$ \\
\hline Esophagectomy & 2,296 & $\begin{array}{l}1,858 \\
(80.9)\end{array}$ & $\begin{array}{l}62.3 \\
(9.5)\end{array}$ & $2.4(1.7)$ & $20.0(3.0)$ & $93(4.1)$ & 221 (9.6) \\
\hline Gastrectomy & 9,777 & $\begin{array}{l}5,695 \\
(58.2)\end{array}$ & $\begin{array}{c}68.8 \\
(12.8)\end{array}$ & $2.0(1.7)$ & $20.3(3.2)$ & 929 (9.5) & $500(5.1)$ \\
\hline Pancreatectomy & 6,148 & $\begin{array}{l}3,255 \\
(52.9)\end{array}$ & $\begin{array}{c}65.0 \\
(11.2)\end{array}$ & $2.1(1.7)$ & $20.6(3.4)$ & $451(7.3)$ & $316(5.1)$ \\
\hline PCI & 280,369 & $\begin{array}{c}209,058 \\
(74.6)\end{array}$ & $\begin{array}{c}66.1 \\
(13.1)\end{array}$ & $1.5(1.4)$ & $20.3(3.2)$ & $\begin{array}{c}190,154 \\
(67.8)\end{array}$ & $33,713(12.0)$ \\
\hline CABG & 23,247 & $\begin{array}{l}19,019 \\
(81.8)\end{array}$ & $\begin{array}{c}67.2 \\
(10.4)\end{array}$ & $2.6(1.8)$ & $20.0(2.8)$ & $6,586(28.3)$ & $4,927(21.2)$ \\
\hline AAA repair & 15,935 & $\begin{array}{l}14,736 \\
(92.5)\end{array}$ & $\begin{array}{l}74.2 \\
(8.9)\end{array}$ & $1.8(1.4)$ & $20.2(3.3)$ & $0.0(0.0)$ & $321(2.0)$ \\
\hline $\begin{array}{l}\text { Carotid } \\
\text { endarterectomy }\end{array}$ & 63,829 & $\begin{array}{l}45,421 \\
(71.2)\end{array}$ & $\begin{array}{l}72.2 \\
(9.8)\end{array}$ & $1.7(1.4)$ & $20.2(3.3)$ & $4,462(7.0)$ & $1,861(2.9)$ \\
\hline $\begin{array}{l}\text { Hip fracture } \\
\text { repair }\end{array}$ & 235,137 & $\begin{array}{l}60,169 \\
(25.6)\end{array}$ & $\begin{array}{c}81.6 \\
(11.4)\end{array}$ & $1.4(1.4)$ & $20.1(3.1)$ & $\begin{array}{l}235,137 \\
(100.0)\end{array}$ & $3,713(1.6)$ \\
\hline
\end{tabular}

a Elixhauser comorbidities include congestive heart failure, cardiac arrhythmias, valvular disease, pulmonary circulation disorders, peripheral vascular disorders, hypertension uncomplicated/complicated, paralysis, other neurological disorders, chronic pulmonary disease, diabetes uncomplicated/complicated, hypothyroidism, renal failure, liver disease, peptic ulcer disease excluding bleeding, AIDS/HIV, lymphoma, metastatic cancer, solid tumor without metastasis, rheumatoid arthritis/collagen vascular diseases, coagulopathy, obesity, weight loss, fluid and electrolyte disorders, blood loss anemia, deficiency anemia, alcohol abuse, drug abuse, psychoses, depression.

PCI percutaneous coronary intervention, CABG coronary artery bypass grafting, AAA abdominal aortic aneurysm

\section{Table 3 Patient outcomes by procedure}




\begin{tabular}{lccc}
\hline & Mortality & Reoperation & Unplanned hospital readmission \\
& $\mathrm{N}(\%)$ & $\mathrm{N}(\%)$ & $\mathrm{N}(\%)$ \\
\hline Colectomy & $3,271(3.8)$ & $6,349(7.4)$ & $6,432(7.5)$ \\
Proctectomy & $848(2.3)$ & $4,760(12.8)$ & $3,909(10.5)$ \\
\hline Esophagectomy & $125(5.4)$ & $346(15.1)$ & $360(15.7)$ \\
\hline Gastrectomy & $451(4.6)$ & $898(9.2)$ & $1,044(10.7)$ \\
\hline Pancreatectomy & $283(4.6)$ & $713(11.6)$ & $34,074(12.2)$ \\
\hline PCI & $6,741(2.4)$ & $41,362(14.8)$ & $1,654(7.1)$ \\
\hline CABG & $573(2.5)$ & $1,762(7.6)$ & $923(5.8)$ \\
\hline AAA repair & $204(1.3)$ & $411(2.6)$ & $3,192(5.0)$ \\
\hline Carotid endarterectomy & $586(0.9)$ & $1,908(3.0)$ & $12,146(5.2)$ \\
\hline Hip fracture repair & $9,059(3.9)$ & $5,827(2.5)$ & \\
\hline
\end{tabular}

PCI percutaneous coronary intervention, CABG coronary artery bypass grafting, AAA abdominal aortic aneurysm

\section{Figures}

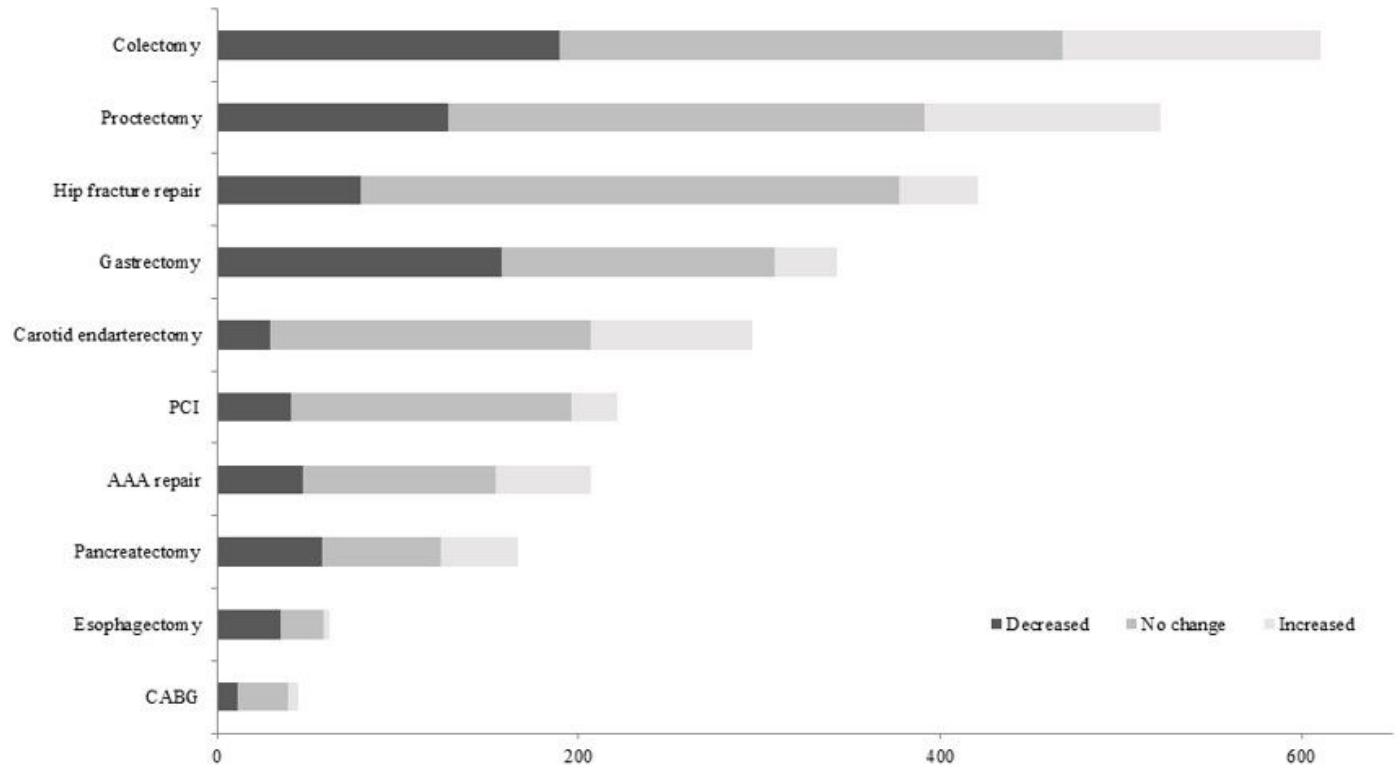

Number of hospitals 
Number of hospitals by trend in volume of procedures between 2010 and 2014. PCl percutaneous coronary intervention, CABG coronary artery bypass grafting, AAA abdominal aortic aneurysm.

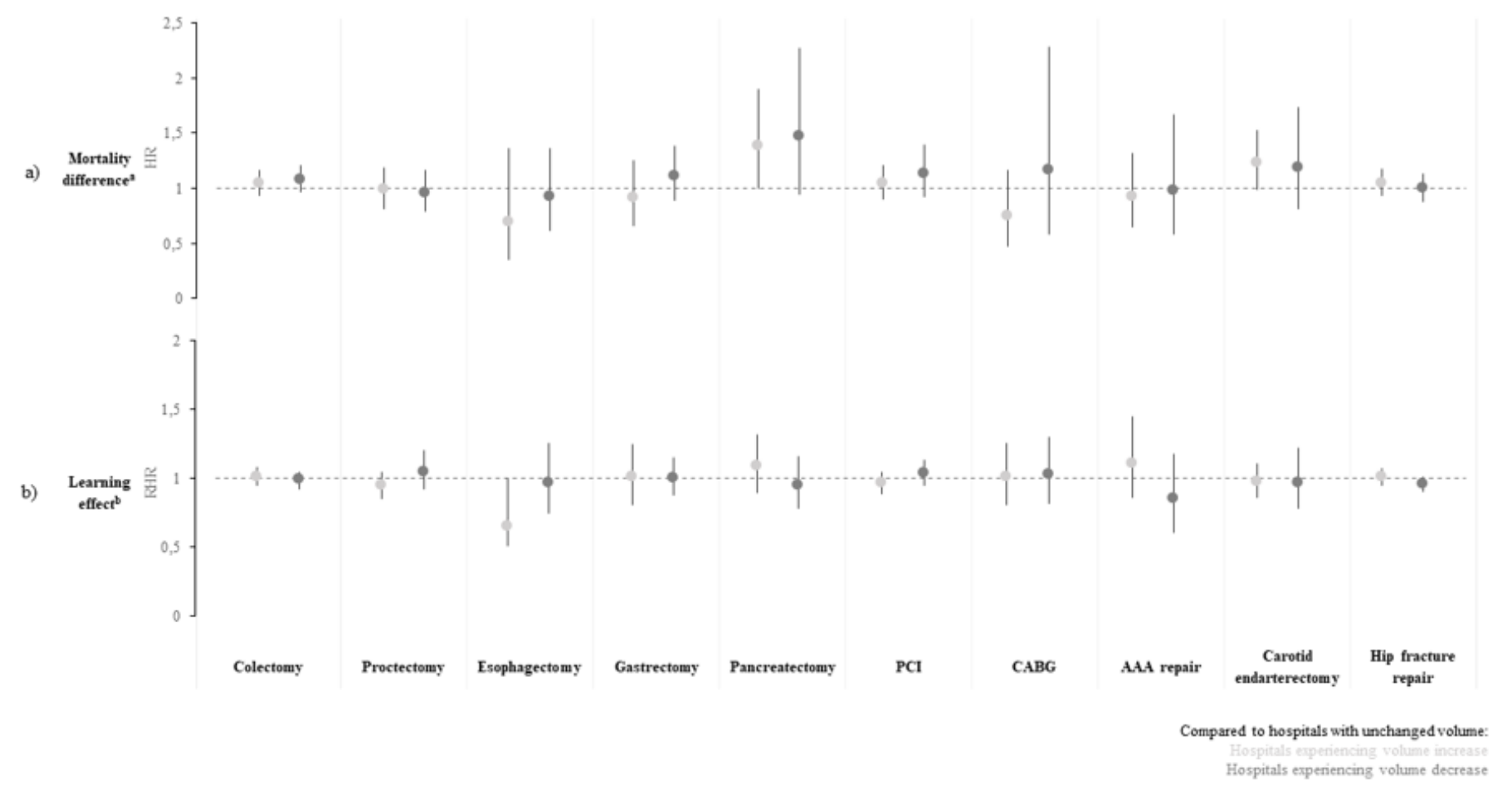

\section{Figure 2}

Mortality difference and learning effect between hospital groups according to trends in procedures volume from 2010 to 2014. CABG coronary artery bypass grafting, AAA abdominal aortic aneurysm, PCl percutaneous coronary intervention. a Hazard-ratios estimated from Cox model with adjustment regarding patient (age, gender, Elixhauser list of comorbidities, type and year of procedure, transfer, emergency admission, and median income) and hospital characteristics (hospital status, volume of procedures, specialization degree, and attraction rate). b Comparison of patient mortality in hospitals with procedure volume increase or decrease over time versus in hospitals with unchanged volume. $c$ Analyse to determine if mortality improve or deteriorate over time with an increasing or decreasing volume of procedures

\section{Supplementary Files}

This is a list of supplementary files associated with this preprint. Click to download.

- Supllnfo.docx 